Abstracta Iranicacta Iranica

Revue bibliographique pour le domaine irano-aryen

Volume 40-41 | 2019

Comptes rendus des publications de 2017-2018

\title{
Caroline Waerzeggers, Maarja Seire (eds). Xerxes and Babylonia. The Cuneiform Evidence
}

\section{Astrid Nunn}

\section{(2) OpenEdition}

1 Journals

\section{Édition électronique}

URL : http://journals.openedition.org/abstractairanica/49375

DOI : 10.4000/abstractairanica.49375

ISBN : 1961-960X

ISSN : 1961-960X

Éditeur :

CNRS (UMR 7528 Mondes iraniens et indiens), Éditions de l'IFRI

Référence électronique

Astrid Nunn, «Caroline Waerzeggers, Maarja Seire (eds). Xerxes and Babylonia. The Cuneiform

Evidence », Abstracta Iranica [En ligne], Volume 40-41 | 2019, document 54, mis en ligne le 30 octobre 2019, consulté le 27 avril 2021. URL : http://journals.openedition.org/abstractairanica/49375 ; DOI : https://doi.org/10.4000/abstractairanica.49375

Ce document a été généré automatiquement le 27 avril 2021.

Tous droits réservés 


\title{
Caroline Waerzeggers, Maarja Seire (eds). Xerxes and Babylonia. The Cuneiform Evidence
}

\author{
Astrid Nunn
}

\section{RÉFÉRENCE}

Caroline Waerzeggers, Maarja Seire (eds). Xerxes and Babylonia. The Cuneiform Evidence.

Leuven : Peeters, 2018, XII-206 p. (Orientalia Lovaniensia Analecta 277)

1 Au cours de ses deux siècles d'existence l'Empire achéménide a connu de nombreuses révoltes. Ce volume s'attache à l'une d'entre elles, celle particulièrement violente de Babylone contre Xerxès dans sa seconde année de règne en 484 av. J.-C. La documentation provient surtout des sources cunéiformes, le point de vue obtenu par le biais des sources grecques étant laissé de côté. On sait également que la répression de révoltes étaient accompagnée de mesures qui théoriquement pourraient avoir laissé des traces archéologiques : destruction de la ville, destruction du temple principal, ou pour Babylone, le détournement de l'Euphrate. Le volume rassemble des études qui illuminent cette révolte sous des aspects définis par les éditrices : la préhistoire de cette révolte, la révolte elle-même et son impact à court et à long terme sur la culture, l'économie et la société babylonienne.

2 Dans l'introduction, Caroline Waerzeggers, Debating Xerxes' Rule in Babylonia, 1-18, résume toutes les recherches faites sur cette révolte et sur les conséquences qu'elle eut pour Babylone. Au final, la culture babylonienne garda son empreinte, malgré la variation des expériences d'une ville à l'autre et malgré l'emprise perse qui semble changer sous Xerxès.

3 Reinard Pirngruber, Towards a Framework for Interpreting Social and Economic Change in Babylonia During the Long $6^{\text {th }}$ Century BCE, 19-33, cherche à comprendre le malaise de la Babylonie avec les Perses dans le développement structurel à long terme plutôt que 
dans la personnalité de Xerxès. L'attitude tant répétée que le remplacement de l'hégémonie babylonienne par celles des Perses n'apporta aucun changement, est inexacte pour l'A. Le déplacement de la capitale et la hausse des prix ne sont que deux aspects peu appréciés des Babyloniens.

Małgorzata Sandowicz, Before Xerxes: The Role of the Governor of Babylonia in the Administration of Justice Under the First Achaemenids, 35-62, se basant sur des textes en partie non publiés, évoque une autre raison pour le mécontentement des Babyloniens. Leur administration fut démantelée et les fonctionnaires babyloniens remplacés par des perses.

5 Michael Jursa, Xerxes: The Case of Sippar and the Ebabbar Temple, 63-72, montre que l'administration de la ville de Sippar était en train de perdre le contrôle des temples babyloniens. En effet, les fonctionnaires de son administration, protégés par l'Etat, furent au fur et à mesure remplacés par des membres du clergé babylonien.

6 Karlheinz Kessler, Uruk: The Fate of the Eanna Archive, the Gimil-Nanāya B Archive, and Their Archaeological Evidence, 73-87, commente et compare l'abandon de trois archives. Le temple de Eanna à Uruk, archives inclues, pourrait bien avoir été abandonné sous Xerxès, même si la tablette la plus récente remonte à la $29^{\text {ème }}$ année de Darius. La dernière tablette des archives de la famille d'Egibi remonte à la $33^{\text {ème }}$ année de ce roi. Enfin la famille de Gimil-Nanāya, au contraire, réussi à se maintenir jusqu'à la gème année de Xerxès.

7 Caroline Waerzeggers, The Network of Resistance: Archives and Political Action in Babylonia Before $484 B C E, 89-133$, étudie la manière dont se créèrent les archives: d'abord décentralisées et organiques avant 484 , elles devinrent homogènes et centralisées. Le corpus dévoile ainsi non seulement une forme de développement dans l'action politique mais aussi une fracture sociale.

8 Mathieu Ossendrijver, Babylonian Scholarship and the Calendar During the Reign of Xerxes, 135-163, nous avertit de ne pas interpréter le manque de textes après les premières années de Xerxès comme un vide en Babylonie. En effet les textes astraux de la fin de l'époque achéménide et de l'époque hellénistique prouvent que les différents projets concentrés dans les temples babyloniens ont continué à exister. Ceci implique d'une part que le rituel des temples babylonien continua, et d'autre part, qu'il y avait une communication positive entre la Babylonie et la Perse.

9 Johannes Hackl, The Esangila Temple During the Late Achaemenid Period and the Impact of Xerxes' Reprisals on the Northern Babylonian Temple households, 165-187, propose de faire remonter les changements administratifs au règne de Xerxès. En effet, le système de prébende pour administrer les temples semble ne plus exister à Babylone et Borsippa après Xerxès, alors qu'il continue d'exister à Uruk. Ceci indique une réaction perse «sur mesure».

10 Paul-Alain Beaulieu, Uruk Before and After Xerxes: The Onomastic and Institutional Rise of the God Anu, 189-206, étudie de près la transformation du panthéon à Uruk. Il constate que la domination d'Ishtar faiblit dès Nabonide pour laisser place à celle de Anu. L'établissement définitif de ce changement semble coöncider avec le règne de Xerxès. La monté d'Anu sous Nabonide pourrait être l'expression d'un mouvement populaire contre la dynastie babylonienne. Xerxès l'aurait alors récupéré pour instaurer sa propre autorité et promouvoir une identité locale. 


\section{AUTEURS}

\section{ASTRID NUNN}

Université de Munich 